\title{
DDT limits of ethanol-air in an obstacles-filled tube
}

\section{Andrés Armando Mendiburu Zevallos, Gabriel Ciccarelli \& João A.}

Carvalho Jr.

To cite this article: Andrés Armando Mendiburu Zevallos, Gabriel Ciccarelli \& João A. Carvalho Jr. (2018): DDT limits of ethanol-air in an obstacles-filled tube, Combustion Science and Technology, DOI: $10.1080 / 00102202.2018 .1477770$

To link to this article: https://doi.org/10.1080/00102202.2018.1477770

\section{曲 Published online: 11 Jun 2018.}

Submit your article to this journal $₫$

山 Article views: 31

View Crossmark data ¿ 


\title{
DDT limits of ethanol-air in an obstacles-filled tube
}

Check for updates

\author{
Andrés Armando Mendiburu Zevallos (iD) ${ }^{a}$, Gabriel Ciccarellib, and João A. Carvalho Jr. ${ }^{a}$ \\ aSchool of Engineering, Energy Department, São Paulo University (UNESP), Guaratinguetá, São Paulo, Brazil;

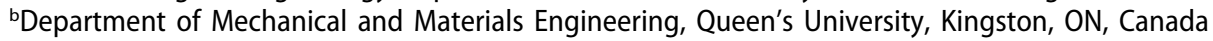

\begin{abstract}
Experiments were performed to study flame acceleration and deflagration-to-detonation transition (DDT) in ethanol-air mixtures in a tube filled with orifice plates with a blockage ratio of 0.44 . Tests were conducted at initial temperatures of 100 and $200^{\circ} \mathrm{C}$, and initial pressures of 60 and $101 \mathrm{kPa}$. Experiments carried out at $60 \mathrm{kPa}$ did not result in DDT, whereas tests performed at $101 \mathrm{kPa}$, at both 100 and $200^{\circ} \mathrm{C}$, resulted in DDT for mixtures in the equivalence ratio range of 1.1-1.3. In a previous study, cell size data of a "double cell structure" have been obtained for mixtures of ethanol-air. Using the $d / \lambda=1$ criterion (that has been confirmed in the tube and orifice plate geometry used in this study with gaseous fuels at room temperature), it was determined that the DDT limit correlates with the ethanol large-cell size reported in the previous study. As a result, for explosion safety purposes, the large-cell size data should be used for assessing the DDT potential of an ethanol-air mixture.
\end{abstract}

\section{ARTICLE HISTORY}

Received 31 October 2017

Revised 18 April 2018

Accepted 13 May 2018

\section{KEYWORDS}

DDT-Limits; Flame

acceleration; Cell size;

Ethanol

\section{Introduction}

Ethanol is a grain alcohol that is an important fuel additive used in the operation of internal combustion engines for transportation. In North America, ethanol is added to gasoline up to $10 \%$ by volume to increase the octane number. In Brazil, most of the automobiles use fuel consisting of either a large fraction of ethanol, or pure ethanol for large transport trucks. Ethanol is also used in the chemical industry as a base chemical for producing organic compounds. Unlike gaseous fuels, the detonability of ethanol has not been studied extensively.

A detonation wave is a multidimensional front consisting of shock waves moving in the forward direction, as well as in the transverse direction (Ciccarelli and Dorofeev, 2008). Chemical reaction is initiated by the adiabatic compression of the mixture processed by the strongest parts of the corrugated lead shock wave. The points where the weaker transverse shocks intersect the lead shock front are commonly referred to as triple-points. There are two "families" of triple-points, where alternating triple-points travel in opposite directions, transversely along the detonation front. When a detonation wave propagates in a tube, the triple-points trace out a cellular pattern on the inner-wall of the tube. This socalled "fish-scale" pattern is captured on a foil that is pre-coated with carbon soot. The average dimension of the cells formed on the foil, $\lambda$, is known as the detonation cell size. Note, the cell size is equivalent to the average spacing between triple-points of the same family. The detonation cell size is an important parameter used to characterize the 
detonability of a fuel. Specifically, the smaller the detonation cell size, the more easily the fuel-oxygen mixture is detonated, e.g., less energy is required for direct initiation (Ciccarelli and Dorofeev, 2008).

In accident scenarios, detonation initiation normally occurs following flame acceleration, whereby a strong shock is produced ahead of the flame. This phenomenon is studied in long ducts equipped with obstacles to promote flame acceleration. Commonly, these types of tests are performed in round tubes filled with orifice plates (Lee et al., 1985). Deflagration-todetonation transition (DDT) requires that the flame accelerates to a velocity on the order of the speed of sound of the combustion products, and that the orifice plate diameter, $d$, must be larger than the mixture's detonation cell size, i.e., $d / \lambda>1$ (Peraldi et al., 1988). Detonation initiation typically occurs as the result of the interaction of the lead shock wave with the obstacle face, or the tube wall (Rainsford and Ciccarelli, 2017).

Ciccarelli and Cross (2016) studied the influence of the orifice blockage ratio (BR) on the DDT limit (i.e., minimum mixture composition resulting in DDT). The BR is defined as the ratio between the cross-sectional area of the tube blocked by the obstacle and the cross-sectional area of the tube; for a tube with diameter $D$, the BR is $B R=1-(d / D)^{2}$. The experiments were carried out inside a stainless-steel tube of $10 \mathrm{~cm}$ diameter and $6.1 \mathrm{~m}$ long with different types of fuels. It was shown that for a BR of 0.44 , the DDT limit correlated with the criterion $d / \lambda>1$, corroborating the experimental findings of Peraldi et al. (1988). Other studies, such as by Kuznetsov et al. (1999), performed with similar BR orifice plates have also confirmed the applicability of the DDT criterion.

The most comprehensive study of detonation waves in ethanol-air mixtures was performed by Diakow et al. (2015) and Diakow (2012). They measured the detonation cell size of ethanol-air mixtures at $101 \mathrm{kPa}$ and temperatures of $30^{\circ} \mathrm{C}$ and $100^{\circ} \mathrm{C}$. Diakow et al. (2015) reported two cell sizes for ethanol-air mixtures. The large cell size $\left(\lambda_{L}\right)$ and small cell size $\left(\lambda_{S}\right)$ were obtained from soot foils $(30.48$ by $50.88 \mathrm{~cm})$ which were inserted into the end of the tube,

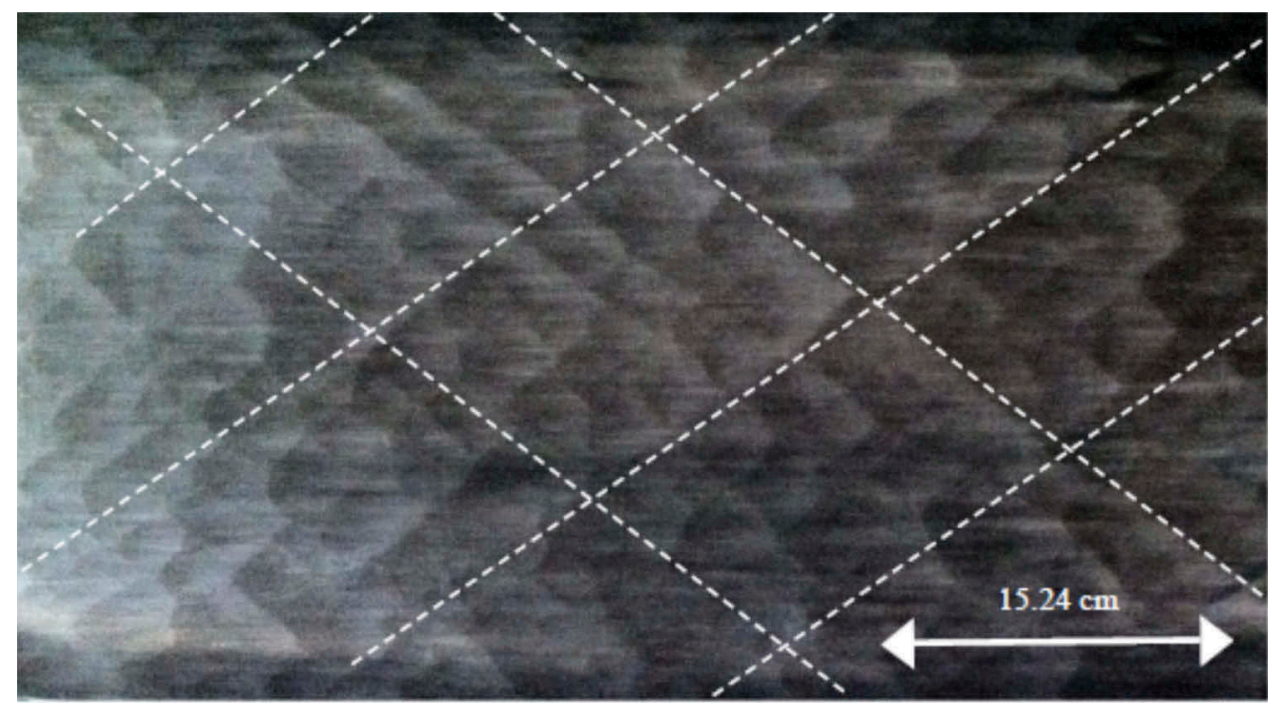

Figure 1. Soot foil showing two-scale cellular structure obtained by Diakow (2012) for an ethanol-air mixture with $9.48 \%$ ethanol concentration at an initial temperature of $373 \mathrm{~K}$ and $100 \mathrm{kPa}$ pressure. 
an example is provided in Figure 1. The dominant mode method, described in Moen et al. (1982), was applied to measure the cell width. The method measures the average lateral spacing between triple-point tracks of the same family, instead of measuring individual cells. The soot foils showed stronger and weaker triple-point tracks (the stronger lines are highlighted by the dotted lines in Figure 1) that were used to come up with two sets of cell size data for a given foil. The size of the small detonation cells varied very little with equivalence ratio (ER), whereas the size of the large cells increased significantly away from the stoichiometric composition of $6.54 \%$ ethanol. At $30^{\circ} \mathrm{C}$, the small cells ranged in size from 27 to $44 \mathrm{~mm}$ for concentrations between $6 \%$ and $10.7 \%$ ethanol. The large cells ranged in size from 86 to 130 $\mathrm{mm}$ for concentrations between $6 \%$ and $8.5 \%$ ethanol. At $100^{\circ} \mathrm{C}$, the small cell sizes raged from 30 to $40 \mathrm{~mm}$ for ethanol concentration between $6.5 \%$ and $12.5 \%$. The large cells ranged in size from 70 to $138 \mathrm{~mm}$ for ethanol concentrations between $6.5 \%$ and $11 \%$. Qualitatively similar foils were obtained by Eaton et al. (2012) for detonations propagating in subatmospheric methanol-oxygen mixtures.

Both sets of triple-point tracks (for the large and small cells) were parallel to each other, so the small cells were not considered to be substructure, as is found in highly irregular structure detonation waves in mixtures with large activation energy (Vasil'ev, 2012). Dualcell structure detonation waves were first identified by Presles et al. (1996) in nitromethane-oxygen mixtures, and later for common fuels mixed with a nitrogen oxide. Vasil'ev (2014) proposed that the addition of a monofuel that releases energy upon decomposition to a fuel oxygen mixture can produce a dual-cell structure detonation wave. Ethanol and methanol were classified as such a monofuel in the paper but this classification was not confirmed with testing. However, in such dual-cell structure detonation waves, the smaller cells are typically an order of magnitude smaller than the large cells and the smaller cells grow in size within the large cell, which is not consistent with the observed cell structure in the Diakow et al. (2015) study.

The short coming of the Diakow et al. (2015) study was that it did not address which measured cell size represents the mixture reactivity governing detonation initiation. From a more practical sense, the study did not determine which set of cell size data should be used for explosion safety. One of the objectives of this study was to determine which set of cell size data should be used for predicting DDT for ethanol-air mixtures. In this study, experiments were performed in a tube filled with orifice plates to obtain the DDT composition limit of ethanol-air mixtures. The tests were carried out in the same $10-\mathrm{cm}$ diameter tube and 0.44 BR orifice plates used in the Ciccarelli and Cross (2016) experiment that confirmed the applicability of the DDT criterion $d / \lambda=1$ for gaseous fuels. Using the DDT composition limits measured in this study for ethanol-air, and the DDT criterion of $d / \lambda=1$, it is possible to determine which cell size data reported by Diakow et al. (2015), i.e., small or large, should be used to predict DDT for ethanol-air mixtures.

\section{Experimental setup}

The experimental setup consisted of a detonation tube and mixing chamber, both of which were heated. The stainless-steel detonation tube had an inner-diameter of $10 \mathrm{~cm}$, a total length of $6.1 \mathrm{~m}$, and a wall thickness of $1.91 \mathrm{~cm}$. It consists of two $3.05-\mathrm{m}$ sections that were fastened together by bolted flanges. The mixing chamber was a cylindrical vessel of 
$50 \mathrm{~cm}$ length and $25 \mathrm{~cm}$ diameter. The mixing chamber is equipped with an impeller powered by a pneumatic motor to mix the constituent gases that are added one at a time. Orifice plates obstacles with $10 \mathrm{~cm}$ outer-diameter and $7.55 \mathrm{~cm}$ inner-diameter $(B R=0.44)$ were placed inside the detonation tube with a spacing of $10 \mathrm{~cm}$ between plates. Ignition of the mixture was via a 500-mJ capacitive discharge system across two electrodes.

The heating system consisted of two parts: a system to heat the detonation tube and another to heat the mixing chamber. The mixing chamber was heated by three high temperature heating tapes, wrapped around the chamber's body and end-flange. The detonation tube was heated by a custom five-zone heating system. The heaters were constructed of ceramic beads with a weave of nichrome wire. Two of these zones heated the pipe sections, while the other three heated the two end-plates and the middle flange pair. The temperature for each zone was maintained via a controller and K-type thermocouples placed between the heating element and the surface of the chamber or tube. The mixture was transferred from the mixing chamber to the tube via a heated $1.27 \mathrm{~cm}$ diameter stainless-steel tube.

The temperature controllers of the mixing chamber were set up to the desired temperature, the maximum temperature attainable by this system was $150^{\circ} \mathrm{C}$ because of the temperature limitations of the magnetic drive for the impeller. The desired temperature on the detonation tube was maintained by setting up five temperature controllers installed into a master controller system. This heating system was able to reach temperatures higher than $300^{\circ} \mathrm{C}$.

The detonation tube was heated overnight to attain a temperature distribution with a uniformity of $25^{\circ} \mathrm{C}$ in the five zones described earlier. On the other hand, the mixing chamber was heated for at least 1.5 hour before the first test could be performed. For the tests at $100^{\circ} \mathrm{C}$, both the mixing chamber and detonation tube were to that temperature. However, for the tests at $200^{\circ} \mathrm{C}$, the mixing chamber was set to $150^{\circ} \mathrm{C}$ and the detonation tube at $200^{\circ} \mathrm{C}$. For the tests at $200^{\circ} \mathrm{C}$, the mixture was allowed to rest for $45 \mathrm{~s}$ after transfer from the mixing chamber in order to heat up to the tube temperature.

Six ionization probes were located along the tube to obtain the flame time-of-arrival, which was subsequently used to calculate the flame velocity between consecutive probes. The distances to the ignition source of the first through the sixth ionization probes were $2.11,2.74,3.66,4.57,5.18$, and $5.79 \mathrm{~m}(7,9,12,15,17$, and 19 feet), respectively. Because the ionization probes are not sensitive to deflagrations with velocities lower than (approximately) $100 \mathrm{~m} / \mathrm{s}$, a photodiode was placed at $4.88 \mathrm{~m}$ from the ignition source to determine whether the flame reached that point or not. A PCB model 113A22 pressure transducer was placed at $5.49 \mathrm{~m}$ from the ignition source to measure pressure time-history and maximum pressure. Finally, strain gauge type pressure transducers $(0.25 \%$ accurate) were used to monitor the mixture preparation in the mixing chamber and the mixture filling in the tube. These pressure transducers measured pressure to a maximum of 4 and 1 bar absolute in the case of the mixing chamber and of the detonation tube, respectively. A schematic representation of the experimental apparatus is provided in Figure 2.

Several ethanol-air mixtures were considered in the experimental work. The ERs $(\phi)$ tested ranged from 0.6 to 1.5 . The initial mixture test conditions inside the tube were $100^{\circ}$ $\mathrm{C}$ and $101 \mathrm{kPa}, 200^{\circ} \mathrm{C}$ and $101 \mathrm{kPa}$, and $100^{\circ} \mathrm{C}$ and $60 \mathrm{kPa}$. These initial conditions allowed for the assessment of the effect of initial temperature and pressure on the DDT limits of ethanol-air. 


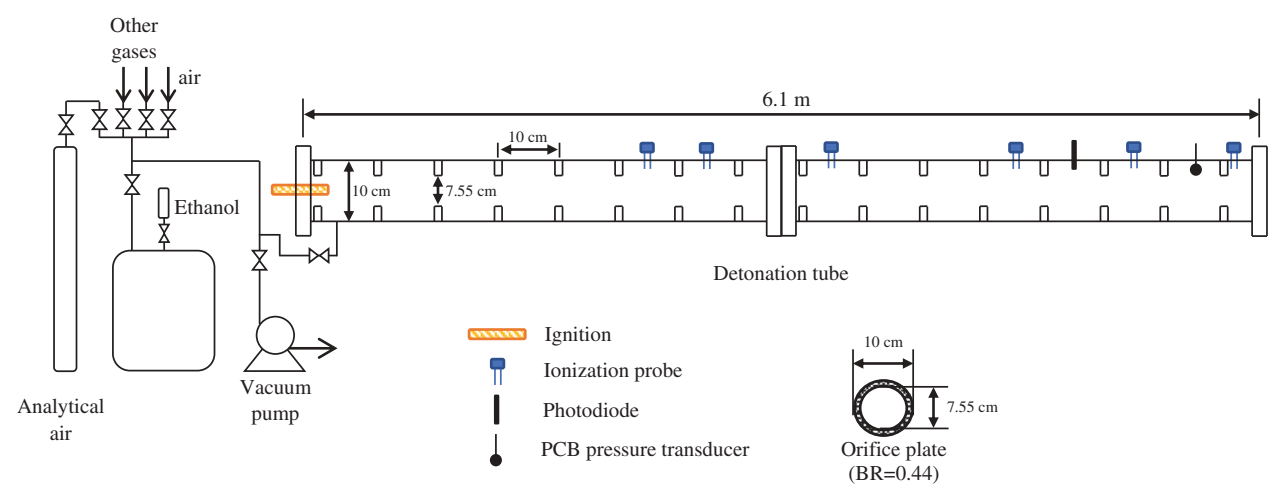

Figure 2. Schematic representation of the experimental apparatus.

The experimental procedure started with the evacuation of the mixing chamber down to a pressure of $0.5 \mathrm{kPa}$, or lower. Then, the mixture constituents were added by the method of partial pressures, the ethanol was admitted first into the chamber up to the desired partial pressure, then the air was admitted until the final pressure was reached. The final pressure inside the mixing chamber was 200 and $280 \mathrm{kPa}$ for the tests run at 60 and $101 \mathrm{kPa}$, respectively. The gas constituents were mixed for $25 \mathrm{~min}$. During this time, the detonation tube was evacuated down to a pressure of $0.5 \mathrm{kPa}$, or lower. After the mixing process was completed, the ethanol-air mixture was admitted into the detonation tube up to the desired pressure of 60 or $101 \mathrm{kPa}$ and the ignition system and data acquisition system were triggered.

The uncertainty of the mixture composition with respect to the ER ranges from 0.005 to 0.010 for mixtures prepared at $280 \mathrm{kPa}$ and from 0.009 to 0.017 for mixtures at $200 \mathrm{kPa}$. The uncertainty takes the higher values for the lower ERs tested. In the "Results and discussions" section, the uncertainties are not always shown in the graphs because they are too small for the scales used to present the results.

Typical signals obtained from the ion probes are presented in Figure 3 . The signals on that figure were obtained for an ethanol-air mixture with $\mathrm{ER}=1.2$ at $100^{\circ} \mathrm{C}$ and $100 \mathrm{kPa}$. The time-of-arrival of the flame is determined by inspection of the sudden drop in voltage associated with short circuiting of the ion probe electrodes by the flame. TecPlot Software allowed to zoom-in to the drop in the signal as much as was necessary. In order to ensure consistency, the time-of-arrival was always measured as the interception of a vertical line superimposed to the initiation of the voltage drop and which intersects the $x$-axis. This procedure of determining the time-of-arrival is exemplified in Figure 3.

\section{Reaction zone length calculations}

The Zeldovich-von Newman-Döring (ZND) detonation model was used to calculate the one-dimensional reaction zone length (Lee, 2008). The open-source software Cantera (Cantera, 2017a) and the Cantera Detonation Tool Box (Cantera, 2017b) were used to 


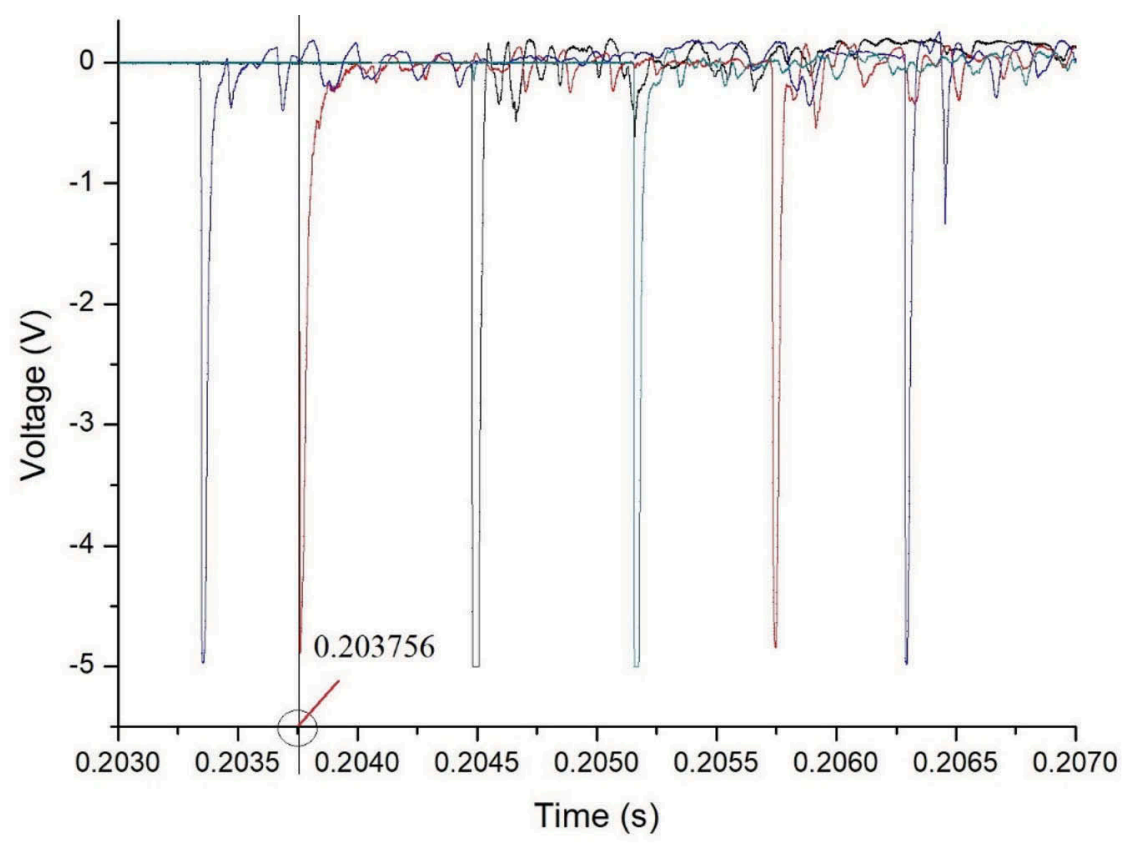

Figure 3. Signals obtained from the ion probes for an ethanol-air mixture with $E R=1.2$ $(7.75 \pm 0.035 \%)$ ethanol concentration at $373 \mathrm{~K}$ and $100 \mathrm{kPa}$.

calculate the ZND detonation wave structure. The kinetic reaction mechanism used was from the work by Zhao et al. (2008).

The ZND model solves a system of differential equations for the conservation of mass, momentum, energy, and species. These equations are presented by Kao and Shepherd (2008) as shown in Eqs. (1)-(4).

$$
\begin{gathered}
\frac{d \rho}{d x}=-\frac{\rho}{w} \frac{\dot{\sigma}}{1-M^{2}} \\
\frac{d w}{d x}=\frac{\dot{\sigma}}{1-M^{2}} \\
\frac{d p}{d x}=-\rho w \frac{\dot{\sigma}}{1-M^{2}} \\
w \frac{d Y_{i}}{d x}=\dot{\Omega}_{i}
\end{gathered}
$$

where $\rho$ is the bulk density, $w$ is the velocity of the unburned gases approaching the wave, $p$ is the pressure, $\dot{\sigma}$ is the thermicity, $M$ is the Mach number, $Y_{i}$ is the $i$ th species mass fraction, and $\dot{\Omega}_{i}$ is the rate of production/destruction of the ith species by chemical reactions.

The thermicity $(\dot{\sigma})$ is defined by Eq. (5) and for a perfect gas, the dimensionless coefficients $\sigma_{i}$ are determined by Eq. (6). 


$$
\begin{gathered}
\dot{\sigma}=\sum_{i=1}^{N} \sigma_{i} \frac{D Y_{i}}{D t} \\
\sigma_{i}=\frac{\bar{W}}{W_{i}}-\frac{h_{i}}{c_{p} T}
\end{gathered}
$$

The ZND reaction zone induction length $\left(\Delta_{i}\right)$ (Kao and Shepherd, 2008), is defined as the distance from the shock wave to the point in the reaction zone where the heat release rate (represented by thermicity) is maximum, which corresponds to the point of maximum temperature gradient.

The ZND calculations performed provide the values of the $\Delta_{i}$ and also of the reaction zone energy pulse width $\left(\Delta_{e}\right)$, which is defined as the half-height width of the thermicity pulse.

The ZND reaction zone induction length can be correlated with the detonation cell size. The simplest approach is to assume that there is a linear relationship between the two, as shown in Eq. (7)

$$
\lambda=A \Delta_{i}
$$

where $A$ is the proportionality constant (Shepherd et al., 1988). The proportionality constant is obtained by anchoring the value of $\Delta_{i}$ at an ER where cell size data are available. The value of $A$ is generally determined at the stoichiometric composition when this approach is applied. However, this is not mandatory, and another composition can be used to obtain the value of $A$.

The calculated reaction zone induction lengths of ethanol-air mixtures over the ER and initial condition range relevant to the experiments are presented in Figure 4. The reaction zone induction length graphs show the minimum $\Delta_{i}$ corresponds to mixtures slightly rich of stoichiometric, around $\varnothing=1.2$. The U-shape of this curve is typical of all detonation wave parameters when plotted versus ER (Lee, 2008), including detonation cell size. The curve indicates that detonation sensitivity is relatively constant around the minimum and decreases for leaner and rich mixtures. Since the DDT limit is correlated with the cell size, one would expect that the DDT limits would correspond to the sudden increase in the reaction zone length with $\varnothing$, which is not observed in Figure 4.

The ZND simulations show that decreasing the pressure or temperature results in a decrease of the reaction rate, which is manifested as an increase in the reaction zone induction length. This increase means that the maximum thermicity is attained over longer distances in the reaction zone of the ZND model. The effect of the initial temperature on $\Delta_{i}$ is small, over the temperature range of interest to the experiments, but the effect of pressure is more pronounced, as shown in Figures 5 and 6. From an explosion safety perspective, this would indicate that the initial temperature over this temperature should not have a strong effect on the DDT limits.

From an experimental point of view, a reduction in the sensitivity to detonation is manifested as an increase in the cell size, which results from lower temperatures and pressures. This can be seen in the Caltech cell size database (Kaneshige and Shepherd, 2005), that shows that the cell size is greater for lower temperatures and pressures. 


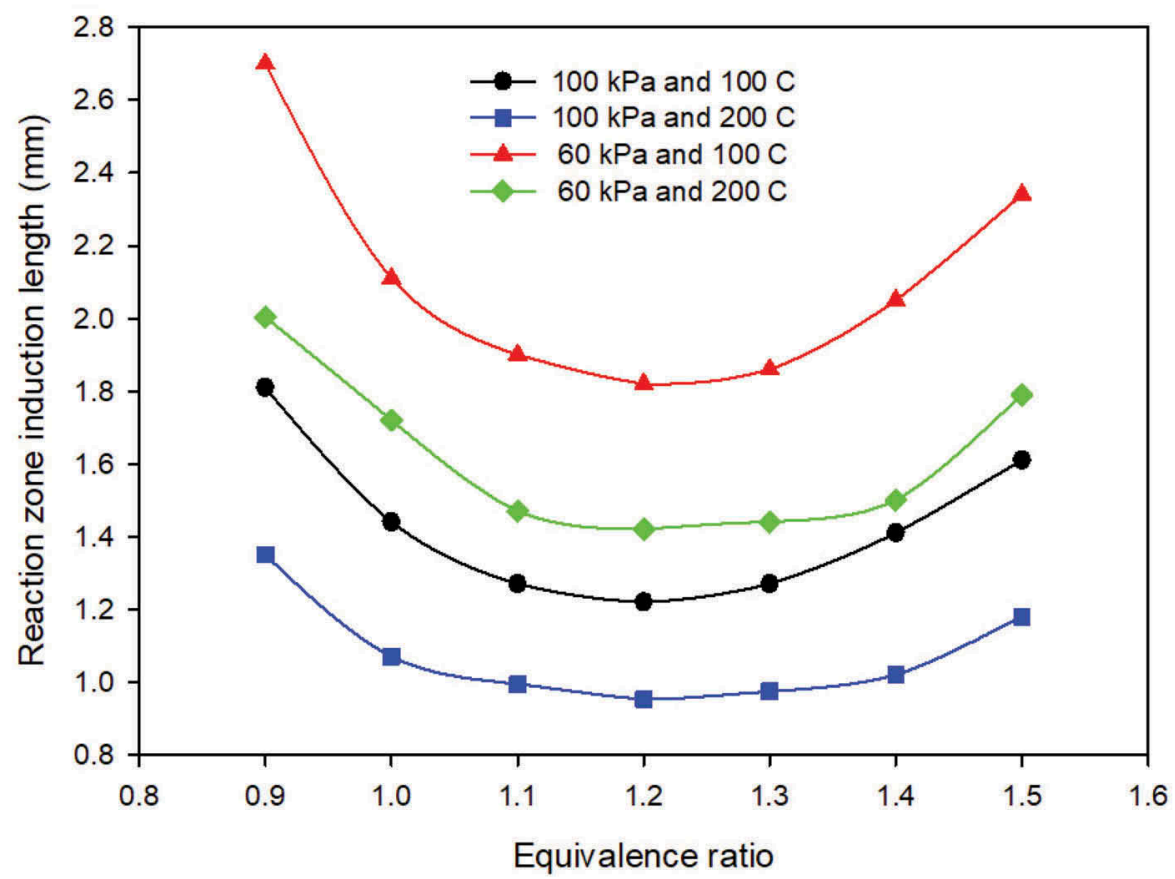

Figure 4. Reaction zone induction length determined by ZND model for ethanol-air mixtures as function of the equivalence ratio.

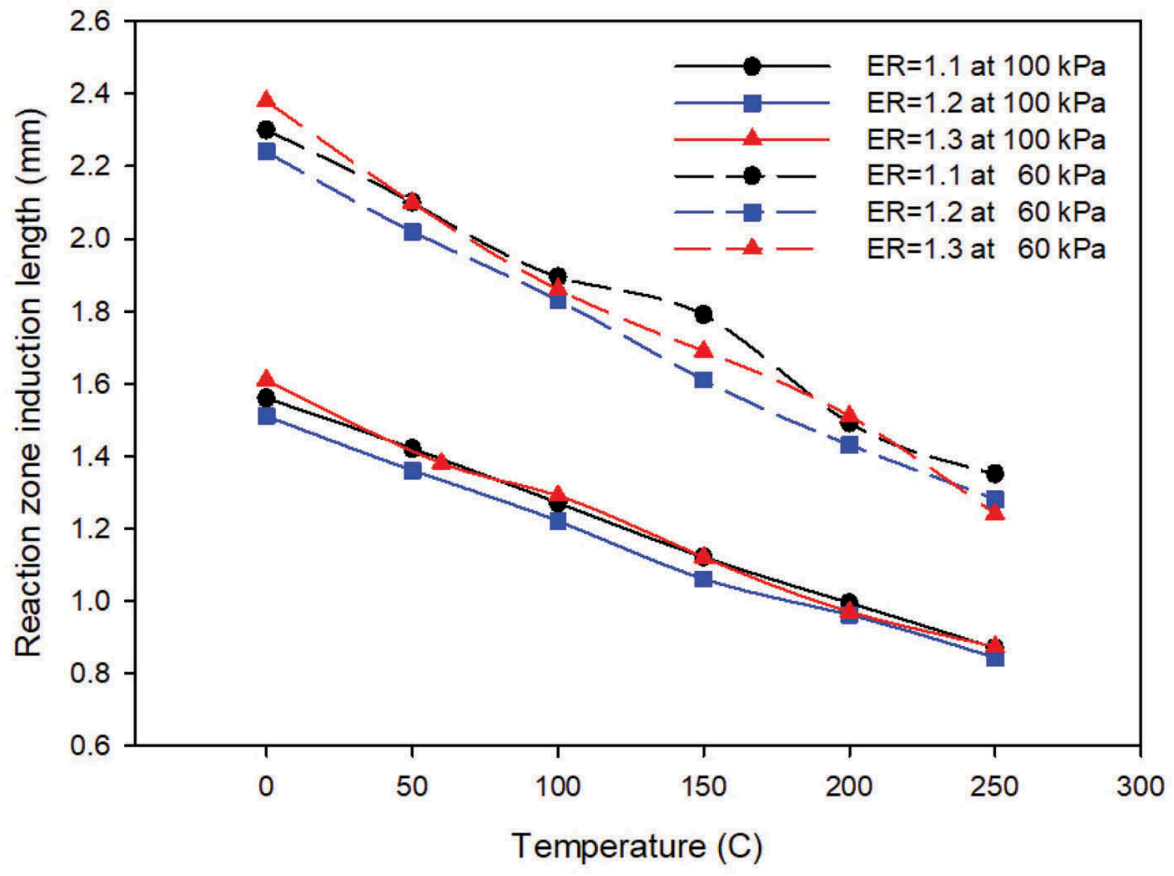

Figure 5. Reaction zone induction length determined by ZND model for ethanol-air mixtures as function of the initial temperature. 


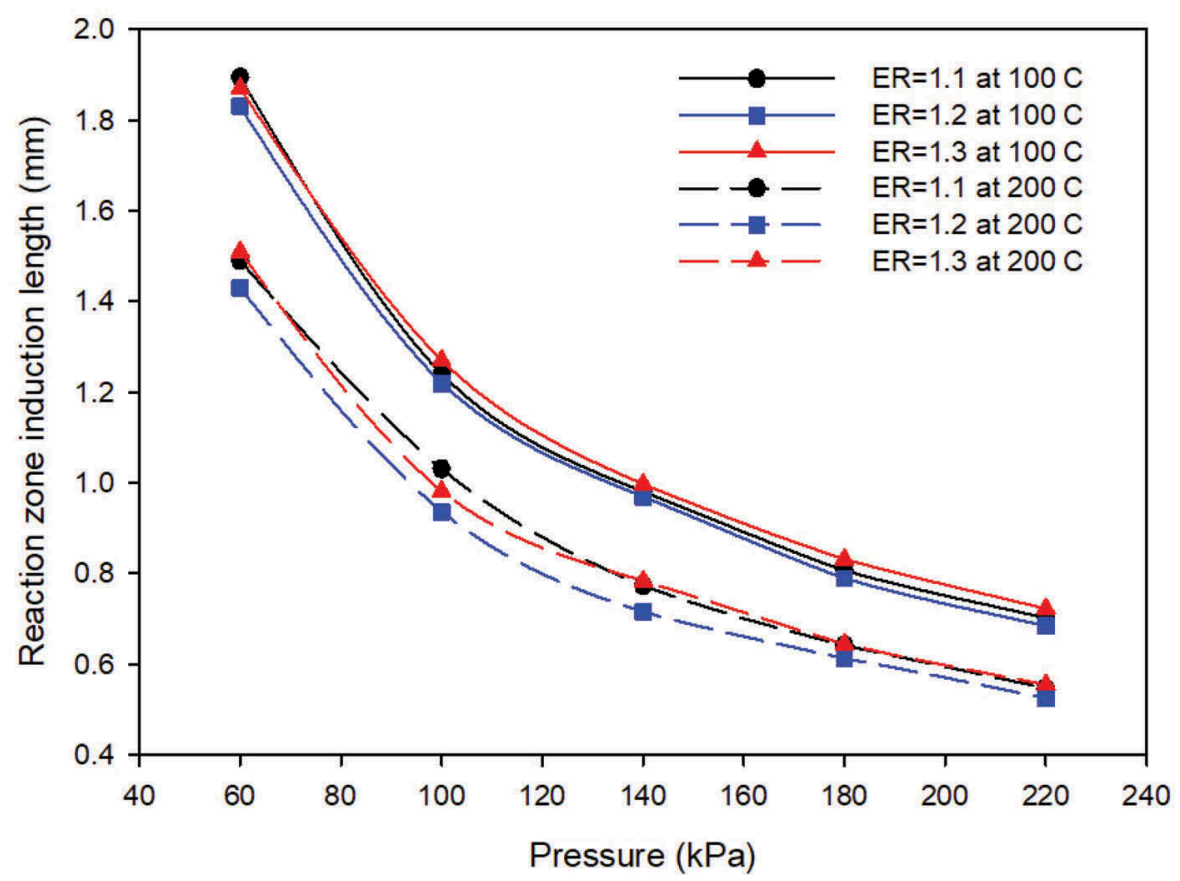

Figure 6. Reaction zone induction length determined by ZND model for ethanol-air mixtures as function of the initial pressure.

The cell size dependence on the initial pressure can be observed in Figure 7(a), where the experimental data plotted corresponds to hydrogen, methane, ethylene, and acetylene (Anderson and Dabora, 1992; Bathel, 1974; Kumar, 1990; Strehlow et al., 1967; Strehlow and Engel, 1969; Desbordes, 1988). Although not plotted in Figure 7(a), the data by Eaton et al. (2012) and by Auffret et al. (2001) show the same behavior for methanol and acetylene, respectively.

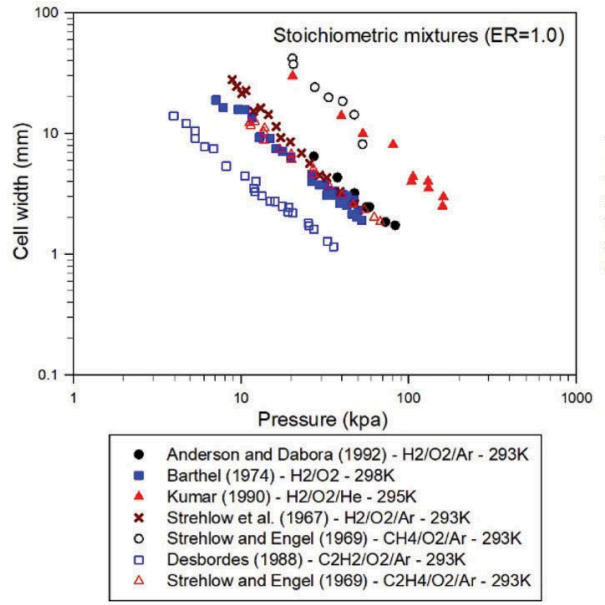

(a) Pressure dependence

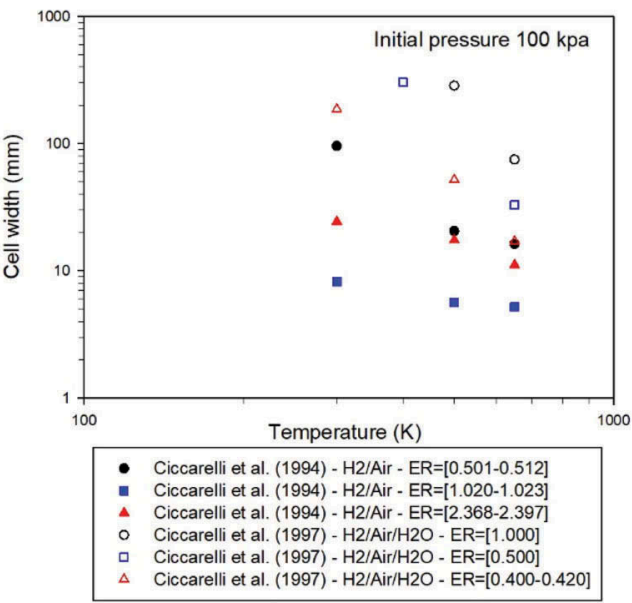

(b) Temperature dependence

Figure 7. Experimental cell size dependence on the initial pressure and temperature for various fuels. 
Similarly, the cell size dependence on the initial temperature can be observed in Figure 7(b) where the experimental data plotted correspond to hydrogen (Ciccarelli et al., 1994, 1997a, 1997b).

Therefore, the experimental cell size data confirm the observations drawn from the ZND simulations, i.e., the decrease of the initial temperature and pressure results in a decrease of the reaction rate, or sensitivity to detonation.

\section{Results and discussions}

The flame and detonation velocities measured along the detonation tube are presented in Figure 8 . Since the main objective of the study is to obtain the DDT limit, which requires the establishment of the propagation regimes, velocity measurements were only made in the latter part of the channel starting at $200 \mathrm{~cm}$ from the ignition source. The location of each velocity data point corresponds to the midspan between two consecutive ion probes. Figure 8 consists of six different graphs corresponding to ERs between 0.9 and 1.4. For each ER, the effects of initial temperature and pressure on the final combustion front velocity are presented via data obtained for 101 and $60 \mathrm{kPa}$, as well as for $100^{\circ} \mathrm{C}$ and $200^{\circ}$ C. The data show that for all the tests performed, independent of the initial temperature or pressure, the flame accelerates to roughly $1000 \mathrm{~m} / \mathrm{s}$ in the first half of the tube. Following this flame acceleration phase, the combustion front settles at a quasi-steady velocity at the end of the second half of the tube. For mixtures with $\varnothing=0.9,1.0$, and 1.4, a maximum velocity of $1000 \mathrm{~m} / \mathrm{s}$ is achieved at $250 \mathrm{~cm}$, followed by a slight drop in velocity terminating at a final velocity in the range of $700-800 \mathrm{~m} / \mathrm{s}$. Combustion waves propagating at this velocity, just below the speed of sound of the products, are known as fastflames, and consist of a precursor shock wave followed by a turbulent flame. Although not presented in Figure 8, tests performed at 60 and $100 \mathrm{kPa}$ with $\varnothing=0.8$ and 1.5 showed the same behavior.

For more reactive mixtures, e.g., $\varnothing=1.1,1.2$, and 1.3, DDT occurred in the second half of the tube for tests performed at $101 \mathrm{kPa}$. For the tests performed at $100^{\circ} \mathrm{C}$, a peak velocity of $1400 \mathrm{~m} / \mathrm{s}$ was achieved at $250 \mathrm{~cm}$. This velocity is well above the speed of sound of the products (that represents a maximum velocity for a flame), and therefore DDT occurred under these test conditions; however, the exact location of the DDT event is not known due to the absence of ion probes in the first $200 \mathrm{~cm}$ of the tube. As has being observed in many studies, following the DDT event the detonation velocity decays slightly eventually achieving a quasi-steady velocity.

For tests performed at $100 \mathrm{kPa}$ and $200^{\circ} \mathrm{C}$, the flame acceleration phase is extended. This lower rate of flame acceleration, associated with elevated initial mixture temperature, was also observed in experiments performed with hydrogen-air (Ciccarelli et al., 1997). They proposed that this effect was due to a decrease in the expansion ratio across the flame associated with higher initial temperatures. For the tests at $200^{\circ} \mathrm{C}$, the location of the DDT event is well defined, and as in the tests at $100^{\circ} \mathrm{C}$, this is followed by a drop in the detonation velocity until reaching the end of the tube. DDT was not observed for tests performed with these three mixture compositions at $60 \mathrm{kPa}$.

To identify the detonation limits, the average flame velocity measured in the second half of the tube is plotted in Figure 9. Also plotted is the calculated Chapman-Jouguet (CJ) detonation velocity $\left(V_{C J}\right)$ and the speed of sound of the combustion products. As 

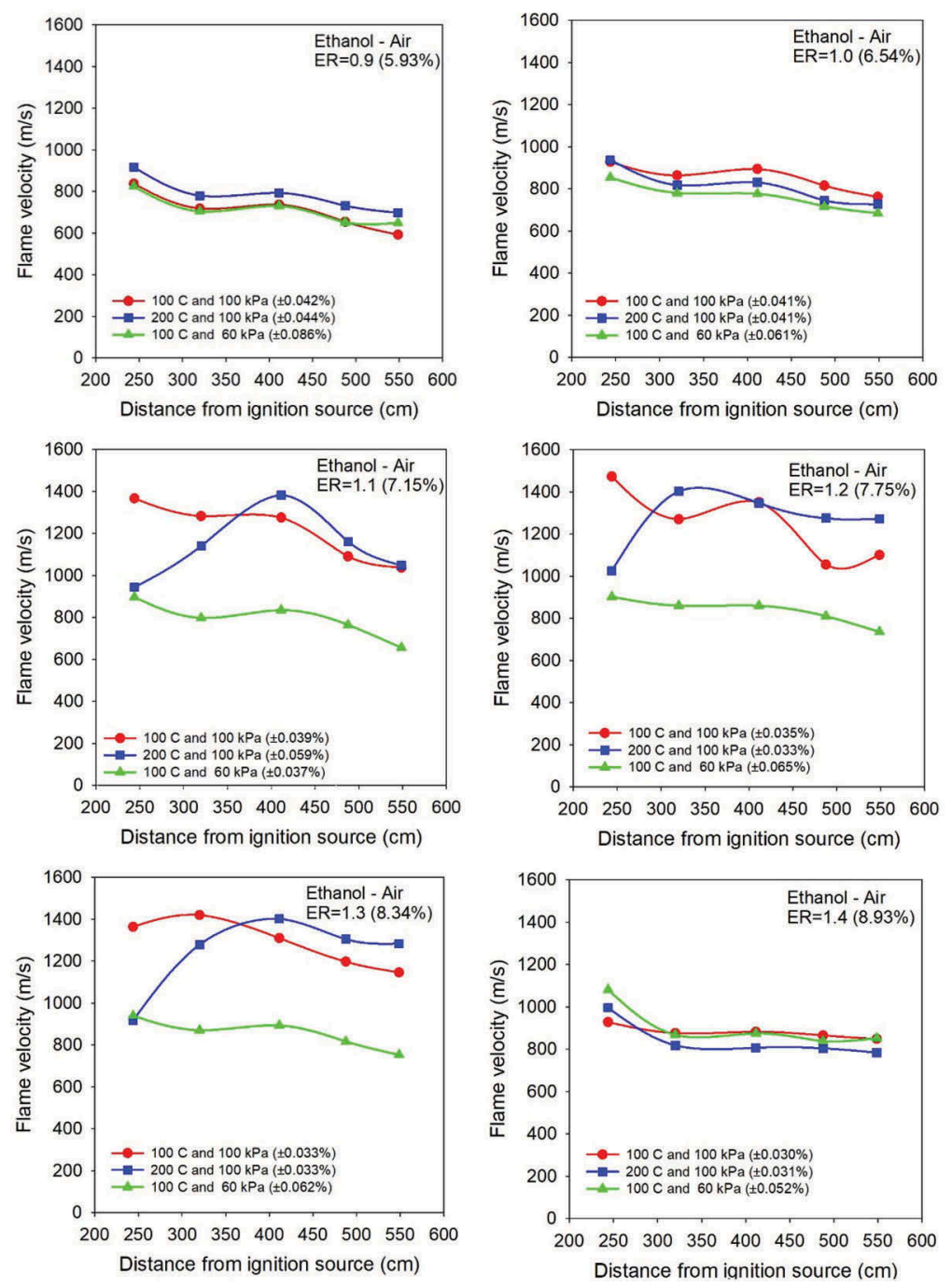

Figure 8. Flame velocities along the detonation tube for ethanol-air mixtures at different initial conditions and at different equivalence ratios.

detailed by Peraldi et al. (1988), a combustion front terminal velocity between the speed of sound of the products and the CJ detonation velocity is referred to as a "quasidetonation." The severe detonation velocity deficit (relative to the CJ value) observed in the data is due to the repeated detonation failure and reinitiation caused by the interaction of the detonation wave and the orifice plates (Rainsford and Ciccarelli, 2017). Quasi-detonation propagation in the second half of the tube was observed for mixtures with $\varnothing=1.1-1.3$, at $101 \mathrm{kPa}$ for both $100^{\circ} \mathrm{C}$ and $200^{\circ} \mathrm{C}$. This insensitivity with initial temperature is consistent with the $\mathrm{ZND}$ reaction zone length calculations. Therefore, these two compositions define the lean and rich DDT limits, respectively. For all the mixtures tested at $60 \mathrm{kPa}$, the velocity remained below the product speed of sound and thus are classified as fast-flames. 

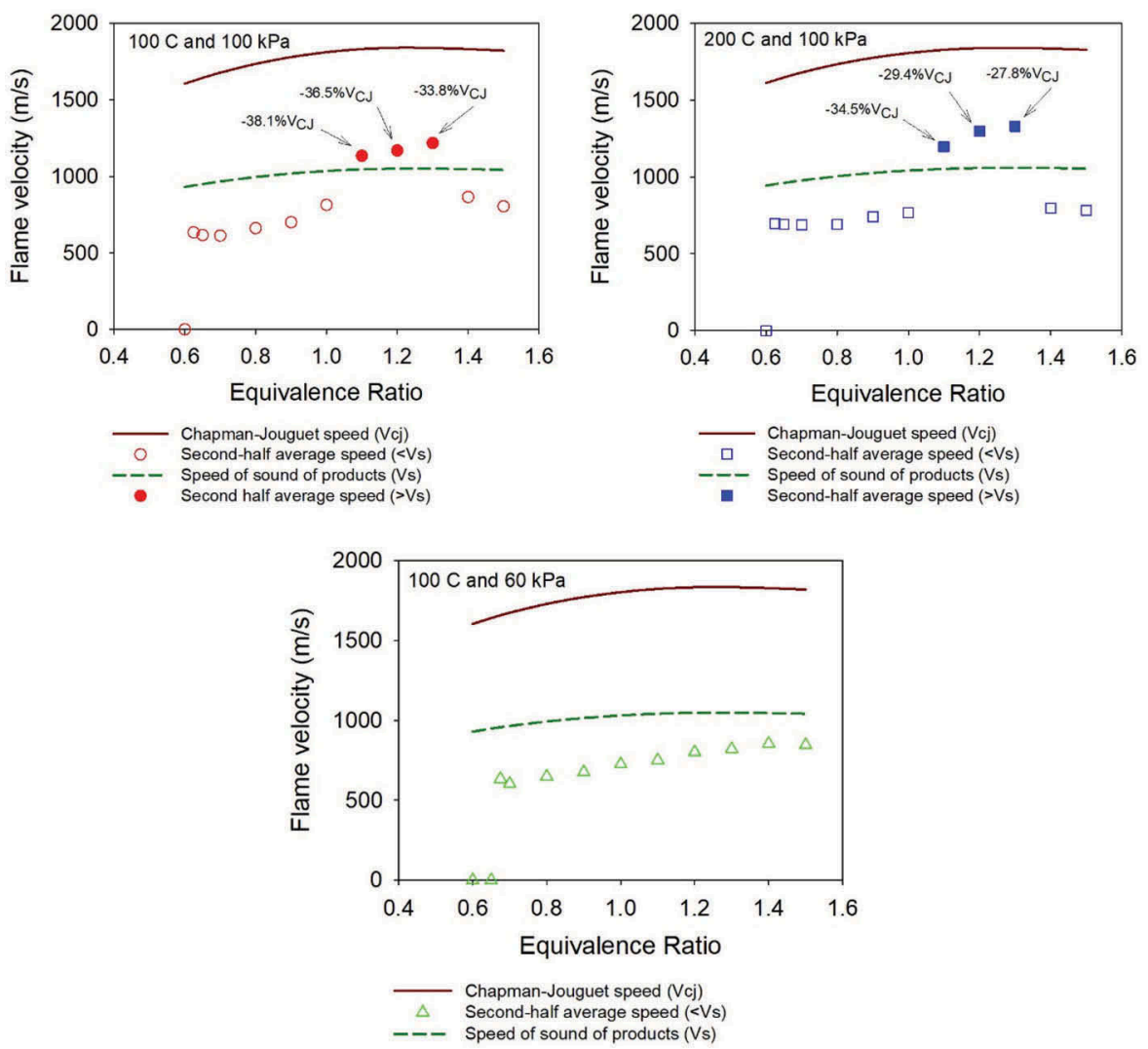

Figure 9. Average flame velocities in the second half of the detonation tube for different initial conditions and different equivalence ratios.

Table 1. Detonation limits of ethanol-air mixtures at different initial conditions.

\begin{tabular}{|c|c|c|c|c|c|}
\hline Reference & Mixture & $p(\mathrm{kPa})$ & $T\left({ }^{\circ} \mathrm{C}\right)$ & Lower limit (\%) & Upper limit (\%) \\
\hline This work & Ethanol-air & 100 & 100 & $\begin{array}{c}7.15( \pm 0,039) \\
(\phi=1.1 \pm 0.006)\end{array}$ & $\begin{array}{c}8.34( \pm 0.033) \\
(\phi=1.3 \pm 0.005)\end{array}$ \\
\hline This work & Ethanol-air & 100 & 200 & $\begin{array}{c}7.15( \pm 0,037) \\
(\phi=1.1 \pm 0.006)\end{array}$ & $\begin{array}{c}8.34( \pm 0.033) \\
(\phi=1.3 \pm 0.006)\end{array}$ \\
\hline Diakow et al. (2015) & Ethanol-air & 100 & 30 & $\begin{array}{c}6.00 \\
(\phi \cong 0.91)\end{array}$ & $\begin{array}{c}8.50 \\
(\phi \cong 1.33)\end{array}$ \\
\hline Diakow et al. (2015) & Ethanol-air & 100 & 100 & $\begin{array}{c}6.50 \\
(\phi \cong 1.0)\end{array}$ & $\begin{array}{c}8.50 \\
(\phi \cong 1.33)\end{array}$ \\
\hline
\end{tabular}

The detonation limits identified in the present study are compared to those obtained in the work by Diakow et al. (2015) in Table 1. In the case of the lean detonation limit, in the present study a value of $7.15 \%$ ethanol was obtained at $100 \mathrm{kPa}$ for both $100^{\circ} \mathrm{C}$ and $200^{\circ} \mathrm{C}$. Diakow et al. (2015) obtained a value $6.5 \%$ of ethanol concentration for the lean detonation limits at $101 \mathrm{kPa}$ and an initial temperature of $100^{\circ} \mathrm{C}$. In the case of the rich detonation limit, the values obtained in the present work $(8.34 \%$ ethanol) and that obtained by Diakow et al. (2015) (8.5\% ethanol) are very similar. It should be noted that the main purpose of the experiments performed by Diakow et al. (2015) was to 
measure detonation cell size, and not to investigate DDT. In their experiment, only the first half of the tube contained orifice plates to promote flame acceleration and DDT. Subsequently, the detonation stabilized at the CJ velocity in the obstacle-free second half of the tube, where the soot foil was located. In the present study, DDT is studied, so the entire tube was filled with orifice plates. The difference in the measured lean DDT limit between the present study and the Diakow et al. study could be attributed to DDT occurring in the obstacle-free second half of the tube in the Diakow et al. experiments. Since the tube diameter is larger than the orifice diameter, a larger cell size can be accommodated, and hence a lower lean limit can result. As proposed by Lee (2008), several experimental studies have demonstrated that there is a "paradox" regarding wallroughness and obstacles effects on detonation waves. While on one hand, the DDT distance can be shortened by the presence of obstacles; on the other hand, the detonation velocity could present a deficit as high as $50 \%$ of the CJ velocity. Since the detonation initiation mechanism in this study is the same as in Diakow et al. (2015), it is evident that a detonation can propagate into a smooth-walled tube while it could fail if it propagates into an obstacles-filled tube.

In the work by Knystautas et al. (1986), a flame was accelerated by using orifice plates as obstacles and then this flame was allowed to propagate into a smooth-walled tube section, and it was observed that for the transition to detonation to occur, the criterion $\lambda / D \geq 1$ had to be met. In the work by Peraldi et al. (1988), the tube was completely filled with obstacles (orifice plates) and the criterion for the transition to detonation was that $\lambda / d \leq 1$. Therefore, in both studies, the values of $\lambda / D$ and $\lambda / d$ were close to unity, except for some mixtures of ethylene with air and acetylene with air. Therefore, Lee (2008) stated that the criterion was $\lambda / D \approx 1$ or $\lambda / d \approx 1$, and regarded the deviations observed with some of the ethylene-air and acetylene-air data to be associated with cell size measurement uncertainty.

On the studies by Cross and Ciccarelli (2015) and by Ciccarelli et al. (2017), the detonation propagation limits were determined by initiating a detonation using an acetylene-oxygen driver in an obstacles-free tube section and letting the detonation wave propagate into an obstacles-filled tube section. The criterion that $\lambda / d \approx 1$ was further established in these two studies. Therefore, this criterion will be applied in the present study.

Cell size data for the detonation limit mixtures obtained in this study, i.e., $\varnothing=1.1$ and 1.3 were not reported in Diakow et al. (2015). The cell size at these compositions were obtained by interpolation of the reported data using the ZND reaction zone induction length $\left(\Delta_{i}\right)$. The value of scaling factor $A$ was obtained based on the cell size measurements at $\varnothing=1.15$. The two scaling factors were found to be $A_{L}=67.5$ and $A_{s}=24.2$, for the large and small cells, respectively. The Diakow et al. (2015) $100^{\circ} \mathrm{C}$ cell size data, along with the predicted detonation cell sizes based on these scaling values are plotted in Figure 10. The experimentally measured cell size data is well correlated with the ZND reaction zone length. The only exception is the large cell size data point for $\emptyset=1$ that appears to be an outlier.

The values of $d / \lambda$ for all the ethanol-air mixtures tested at $101 \mathrm{kPa}$ and $100^{\circ} \mathrm{C}$ are provided in Table 2. For the DDT limits measured in the present study, i.e., $1.1<\varnothing<1.3$, the $d / \lambda$ values for the large and small cell sizes are $0.88 \leq d / \lambda_{L} \leq 0.92$ and $2.46 \leq d / \lambda_{L} \leq 2.56$, respectively. Recall, based on the study of Cross and Ciccarelli (2015), performed in the same setup with different gaseous fuels, it was established that the DDT limit corresponds to 


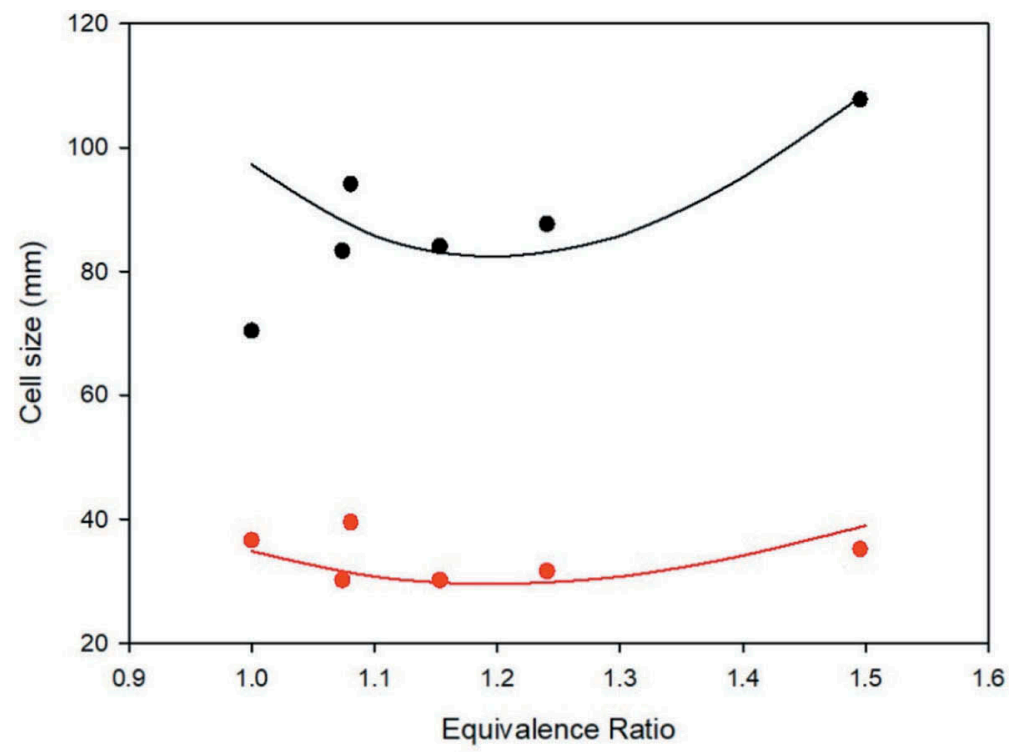

Scaled RZL $(A=67.5)$
Scaled RZL $(A=24.2)$
Measured large cell [Diakow (2012)]
Measured small cell [Diakow (2012)]

Figure 10. Detonation cell size measured by Diakow (2012) and predicted using the ZND model for mixtures at $100 \mathrm{kPa}$ and $100^{\circ} \mathrm{C}$.

Table 2. Cell size as function of equivalence ratio for ethanol-air mixtures at $100 \mathrm{kPa}$ and $100^{\circ} \mathrm{C}$.

\begin{tabular}{|c|c|c|c|c|c|c|c|c|c|c|c|}
\hline \multicolumn{6}{|c|}{ Experimental results (Diakow, 2012) } & \multicolumn{6}{|c|}{ Calculated results (this work) } \\
\hline ER & Fuel (\%) & $\lambda_{L}(\mathrm{~mm})$ & $\lambda_{S}(\mathrm{~mm})$ & $d / \lambda_{L}$ & $d / \lambda_{S}$ & ER & $\begin{array}{c}\begin{array}{l}\text { Fuel } \\
(\%)\end{array} \\
\end{array}$ & $\begin{array}{c}\lambda_{L}^{\mathrm{a}} \\
(\mathrm{mm})\end{array}$ & $\begin{array}{c}\lambda_{S}{ }^{\mathrm{b}} \\
(\mathrm{mm})\end{array}$ & $d / \lambda_{L}$ & $d / \lambda_{s}$ \\
\hline 1.00 & 6.54 & 70.40 & 36.64 & 1.07 & 2.06 & 1.00 & 6.54 & 97.21 & 34.85 & 0.78 & 2.17 \\
\hline 1.07 & 6.99 & 83.33 & 30.17 & 0.91 & 2.50 & 1.10 & 7.15 & 85.74 & 30.73 & 0.88 & 2.46 \\
\hline 1.08 & 7.03 & 94.11 & 39.51 & 0.80 & 1.91 & 1.20 & 7.75 & 82.36 & 29.52 & 0.92 & 2.56 \\
\hline 1.15 & 7.47 & 84.05 & 30.17 & 0.90 & 2.50 & 1.30 & 8.34 & 85.74 & 30.73 & 0.88 & 2.46 \\
\hline 1.24 & 7.99 & 87.64 & 31.61 & 0.86 & 2.39 & 1.40 & 8.93 & 95.19 & 34.12 & 0.79 & 2.21 \\
\hline 1.50 & 9.48 & 107.76 & 35.20 & 0.70 & 2.14 & 1.50 & 9.51 & 108.69 & 38.96 & 0.69 & 1.94 \\
\hline
\end{tabular}

${ }^{\mathrm{a} S c a l i n g}$ factor $A_{L}=67.5 ;{ }^{\mathrm{b}}$ scaling factor $A_{s}=24.2$.

the condition $d / \lambda \approx 1$. Considering the typical $\pm 50 \%$ uncertainty on cell size data, the $d / \lambda$ value corresponding to the large cells is consistent with the $d / \lambda \approx 1$ DDT correlation, but not the small cell size data. As a result, one can conclude that in the present study the cellular structure corresponding to the large cells should be used to predict the DDT limit. From an explosion safety perspective, this yields narrower DDT composition limits.

\section{Conclusions}

DDT experiments were performed in ethanol-air at $100^{\circ} \mathrm{C}$ and $200^{\circ} \mathrm{C}$ in a tube filled with $0.44 \mathrm{BR}$ orifice plates. Tests performed at $60 \mathrm{kPa}$ and $100^{\circ} \mathrm{C}$ resulted in fast-flames, 
characterized by velocities below the speed of sound of the products. However, tests performed at $100 \mathrm{kPa}$, at both $100^{\circ} \mathrm{C}$ and $200^{\circ} \mathrm{C}$, resulted in DDT for mixtures in the range of $1.1<\varnothing<1.3$. These results are in line with the strong effect of initial pressure and the weak effect of the temperature on the ZND reaction zone induction length over the range of experimental test conditions. Using the $d / \lambda \approx 1$ criterion it was shown that the large cell size data reported by Diakow et al. (2015) should be used in the future to predict DDT for explosion safety applications.

\section{Funding}

The authors are grateful to FAPESP (Fundação de Amparo à Pesquisa do Estado de São Paulo) for support of this work through Project 2015/23351-9 and 2015/25435-5.

\section{ORCID}

Andrés Armando Mendiburu Zevallos (10) http://orcid.org/0000-0003-4733-625X

\section{References}

Anderson, T.J., and Dabora, E.K. 1992. Measurements of normal detonation wave structure using Rayleigh imaging. Int. Symp. Combust., 24(1), 1853-1860. doi:10.1016/S0082-0784(06)80217-1.

Auffret, Y., Desbordes, D., and Presles, H.N. 2001. Detonation structure and detonability of C2H2O2mixtures at elevated initial temperature. Shock Waves, 11(2), 89-96. doi:10.1007/PL00004069.

Bathel, H.O. 1974. Predicted spacings in hydrogen-oxygen-argon detonations.pdf. Phys. Fluids, 17 (8), 1547-1553. doi:10.1063/1.1694932.

Cantera. (2017a) Chemical kinetics, thermodynamics, transport properties. Available at: http://www. cantera.org/docs/sphinx/html/index.html (Accessed: 4 October 2017).

Cantera. (2017b) Detonation tool box. Available at: http://shepherd.caltech.edu/EDL/public/cantera/ html/SD_Toolbox/(Accessed: 4 October 2017).

Ciccarelli, G., et al. 1994. Detonation cell size measurements and predictions in hydrogen-air-steam mixtures at elevated temperatures. Combust. Flame, 99(2), 212-220. doi:10.1016/0010-2180(94) 90124-4.

Ciccarelli, G., Ginsberg, T.G., and Boccio, J.L. 1997a. The influence of initial temperature on the detonability characteristics of hydrogen-air-steam mixtures*. Combust. Sci. Technol., 128(1-6), 181-196. doi:10.1080/00102209708935708.

Ciccarelli, G., Ginsberg, T., Boccio, J. L., Finfrock, C., Gerlach, L., Tagawa, H., Malliakos, A. et al. (1997b) Detonation cell size measurements in high-temperature hydrogen-air-steam mixtures at the BNL high-temperature combustion facility. Technical Report NUREG/CR-6391, BNLNUREG-52482, Upton.

Ciccarelli, G., et al. 2017. Effect of orifice plate spacing on detonation propagation. J. Loss Prev. Ind., 49, 739-744. doi:10.1016/j.jlp.2017.03.014.

Ciccarelli, G., and Cross, M. 2016. On the propagation mechanism of a detonation wave in a round tube with orifice plates. Shock Waves. Springer Berlin Heidelberg, 26(5), 587-597. doi:10.1007/ s00193-016-0676-6.

Ciccarelli, G., and Dorofeev, S. 2008. Flame acceleration and transition to detonation in benzene-air mixtures. Combust. Flame, 34, 499-550. doi:10.1016/S0010-2180(98)00014-5.

Cross, M., and Ciccarelli, G. 2015. DDT and detonation propagation limits in an obstacle filled tube. J. Loss Prev. Process Ind.. Elsevier Ltd, 36, 380-386. doi:10.1016/j.jlp.2014.11.020.

Desbordes, D. 1988. Transmission of overdriven plane detonations: critical diameter as a function of cell regularity and size. Prog. Astronaut. Aeronaut., 114, 170-185. doi:10.2514/5.9781600865886.0170.0185. 
Diakow, P. 2012. Detonation Characteristics of Dimethyl Ether, Methanol and Ethanol Air Mixtures, Queen's University, Kingston, Canada. https://qspace.library.queensu.ca/handle/1974/7428.

Diakow, P., Cross, M., and Ciccarelli, G. 2015. Detonation characteristics of dimethyl ether and ethanol-air mixtures. Shock Waves, 25(3), 231-238. doi:10.1007/s00193-015-0554-7.

Eaton, R., et al. 2012. Measurement and chemical kinetic model predictions of detonation cell size in methanol-oxygen mixtures. Shock Waves, 22(2), 173-178. doi:10.1007/s00193-012-0359-x.

Kaneshige, M., and Shepherd, J.E. (2005) GALCIT explosion dynamics laboratory detonation database. Available at: http://shepherd.caltech.edu/detn_db/html/db.html (Accessed: 9 April 2018).

Kao, S., and Shepherd, J.E. (2008) Numerical Solution Methods for Control Volume Explosions and ZND Detonation Structure, GALCIT Report FM2006.007, Pasadena. doi:oai:digitalcommons. uconn.edu:dissertations-6482.

Knystautas, R., et al. 1986. Transmission of a flame from a rough to a sooth-walled tube. In Bowen, J., Leyer, J., and Soloukhin, R.I. (eds.) Dynamics of Explosions. Progress in Astronautics and Eronautics, New York, pp. 37-52.

Kumar, R.K. 1990. Detonation cell widths in hydrogen-oxygen-diluent mixtures. Combust. Flame, 80, 157-169. doi:10.1016/0010-2180(90)90124-A.

Kuznetsov, M., et al. 1999. Effect of Obstacle Geometry on Behavior of Turbulent Flames Report FZKA- 6328, Moscow.

Lee, J.H., Knystautas, R., and Chan, C.K. 1985. Turbulent flame propagation in obstacle-filled tubes. Symp. (Int.) Combust., 20(1), 1663-1672. doi:10.1016/S0082-0784(85)80662-7.

Lee, J.H.S. 2008. The Detonation Phenomenon, Cambridge University Press, New York.

Moen, I.O., et al. 1982. Diffraction of detonation from tubes into a large fuel-air explosive cloud. Symp. (Int.) Combust., 19(1), 635-644. doi:10.1016/S0082-0784(82)80238-5.

Peraldi, O., Knystautas, R., and Lee, J.H. 1988. Criteria for transition to detonation in tubes. Symp. (Int.) Combust., 21(1), 1629-1637. doi:10.1016/S0082-0784(88)80396-5.

Presles, H.N., et al. 1996. Gaseous nitromethane and nitromethane-oxygen mixtures: A new detonation structure. Shock Waves, 6(2), 111-114. doi:10.1007/BF02515194.

Rainsford, G., and Ciccarelli, G. 2017. Visualization of detonation propagation in a round tube equipped with orifice plates. Proceedings of the 26th International Colloquium on the Dynamics of Explosions and Reactive Systems, pp. 1-6. Available at: http://icders2017.com/wp-content/ uploads/26th_ICDERS_Program/Oral/26thICDERS_submission_1091.pdf.

Shepherd, J.E., et al. 1988. Analyses of the cellular structure of detonations. Symp. (Int.) Combust., 21(1), 1649-1658. doi:10.1016/S0082-0784(88)80398-9.

Strehlow, R.A., et al. 1967. Transverse wave structure in detonations. Symp. (Int.) Combust., 11(1), 683-692. doi:10.1016/S0082-0784(67)80194-2.

Strehlow, R.A., and Engel, C.D. 1969. Transverse waves in detonations: II structure and spacing in $\mathrm{H} 2-\mathrm{O} 2, \mathrm{C} 2 \mathrm{H} 2-\mathrm{O} 2, \mathrm{C} 2 \mathrm{H} 4-\mathrm{O} 2$, and $\mathrm{CH} 4-\mathrm{O} 2$ systems. AIAA J., 7(3), 323-328.

Vasil'ev, A.A. 2012. Dynamic Parameters of Detonation. In Zhang, F. (ed.) Shock Waves Science and Technology Library, Vol. 6: Detonation Dynamics, Springer, pp. 213-279. doi:10.1007/978-3-64222967-1_4.

Vasil'ev, A.A. 2014. Monofuel as a source of bifurcation properties of multifuel systems. Combust. Explosion Shock Waves, 50(2), 135-143. doi:10.1134/S0010508214020038.

Zhao, Z., et al. 2008. Thermal decomposition reaction and a comprehensive kinetic model of dimethyl ether. Int. J. Chem. Kinet., 40(1), 1-18. doi:10.1002/kin.20285. 